\title{
Reactivity of antibodies to heteroclitic peptides based on the Chlamydia trachomatis major outer-membrane protein
}

\author{
Gunilla Yxfeldt, ${ }^{1}$ Gunnar Fröman, ${ }^{1}$ Per-Anders Mårdh ${ }^{1}$ \\ and Michael E. Ward ${ }^{2}$
}

Author for correspondence: Gunilla Yxfeldt.

1 Institute of Clinical
Bacteriology, Uppsala
University, Box 552, S-751
22 Uppsala, Sweden
2 Molecular Microbiology
Group, Southampton
University Medical School,
Southampton General
Hospital, Tremona Road,
Southampton SO9 4XY, UK

\section{INTRODUCTION}

The effectiveness of peptide vaccines is dependent on their ability to generate site-selective antibody crossreactive with the cognate sequence on the native protein. Short peptides under 20 amino acids in length are essentially disordered structures in water, generating antipeptide antibodies which vary from poor to good binding with the target protein (Satterthwait et al., 1988). This presently unpredictable behaviour has been termed the order-

Abbreviations: EB, elementary body; EIA, enzyme immunoassay; mAb, monoclonal antibody; MOMP, major outer-membrane protein; VS, variable segment.

\begin{abstract}
One problem of peptide vaccines is that antibodies generated against them react poorly with the target sequence on the native protein. Using monoclonal antibodies (mAbs) to the serovar L1 type-specific epitope on the major outermembrane protein of Chlamydia trachomatis as our model in conjunction with the Pin Technology Epitope Scanning technique, we had previously identified the critical binding site at this epitope as DAVP. Amino acid substitution showed that AV were essential residues for binding. A series of structurally related (heteroclitic) peptides retaining AV were synthesized. Some of these were found to be much more reactive with the model $\mathrm{mAb}$ than peptides of cognate sequence. It was hypothesized that the DAVP peptide only approximated to the conformation of the homologous sequence in the native protein, whereas some of the flexible heteroclitic peptides produced conformations which more closely resembled the native constrained sequence. The key question was whether the most reactive heteroclitic peptide would also generate antibody capable of more efficient binding to the native protein. We therefore immunized mice with one of six heteroclitic peptides or one of two native sequence control peptides. The reactivity of these antisera with the peptide immunogens and with native chlamydial elementary bodies was then evaluated by enzyme immunoassay. Pooled antisera to two of the heteroclitic peptides reacted with significantly greater absorbance $(P<0.05)$ and at higher dilution with whole chlamydiae than did pooled antisera to the control peptides. This suggests that heteroclitic peptides may in some circumstances be useful to increase the reactivity of site-specific antibodies with epitopes on the native protein important for vaccine development or for serodiagnosis.
\end{abstract}

Keywords: Chlamydia trachomatis, epitope mapping, major outer membrane protein, peptides, vaccines disorder paradox (Dyson et al., 1987). One possibility is that short-chain peptides form a small proportion of localized organized structure in aqueous solution. This is supported by the observation that particular short peptides have been observed to form helices (Bierzynski et al., 1982) or reverse turns (Dyson et al., 1988) in solution. On this model the effectiveness of short peptides as vaccine immunogens can be approximated to the fraction of peptide which mimics the ordered structure of the cognate sequence in the target protein (Satterthwait et al., 1988). A second possibility is that antibody to a peptide vaccine might induce some rearrangement at the binding site of the target molecule, the induced fit model (Getzoff et al., 1987). For this model there is evidence that the most 
frequently recognized sites for antibody binding on a protein consist of three-dimensional superassemblies with discontinuous binding regions characterized by high local mobility, as well as by convex surface and, frequently, negative electrostatic potential (Geysen et al., 1987). Binding of the antibody molecule, by induced fit, may be able to produce limited conformational changes in both antigen and antibody (Rini $e t$ al., 1992). At least half the residues in a 28 amino acid peptide bound to antipeptide antibody showed considerable mobility (Cheetham et al., 1991). However where the antigen is a protein, such changes will be limited by the balance of inter- and intramolecular forces and constraints.

At present it is not possible to predict by computation the conformation of a peptide immunogen and the antibodies it generates with sufficient accuracy for vaccine design. However the Pin Technology offers a facile method of synthesizing solid-phase peptides corresponding to the target epitope on the native protein. Systematic amino acid replacement within such peptides can then be used to define essential amino acids at the critical binding site which are recognized by antibody to the target epitope. In this paper we test the hypothesis firstly, that alterations of peptide composition surrounding the essential amino acids might enhance the ability of the solid-phase peptide to function as an antigen and, secondly, that these altered heteroclitic peptides might generate antibody of improved reactivity with the native epitope. As our model system, we have explored the binding of serovar L1 specific monoclonal antibodies (mAbs) to the Chlamydia trachomatis major outer-membrane protein.

C. trachomatis is a major cause of genital and ocular infection, with tubal infertility and blindness, respectively, a severe sequelae. Empirical attempts to prevent severe ocular infection (trachoma) in man by vaccination with whole $C$. trachomatis elicited poor protection which was attributed to local, serovar-specific, neutralizing antibody. However there was evidence that vaccination resulted in more severe disease in some individuals on reinfection with trachoma organisms of heterologous serovar (reviewed in Schachter \& Dawson, 1978). Thus the focus of chlamydial vaccine development is the development of a subcomponent vaccine based on recombinant or peptide antigens.

The major outer-membrane protein (MOMP) is the immunodominant antigen at the surface of the infectious chlamydial elementary body (EB) (Caldwell et al., 1981). Comparisons of inferred amino acid sequences of MOMP for 15 serovars of $C$. trachomatis have revealed four variable segments (VS) in the protein (Yuan et al., 1989). VS1 or VS2, depending on the serovar, contain serovarspecific epitopes, while VS4 contains subspecies- and species-specific epitopes (Baehr et al., 1988; Conlan et al., 1988). Antibodies to the surface-exposed serovar and subspecies epitopes in VS1, 2 and 4 are neutralizing, protecting against chlamydial infection in vitro and in the primate eye (Zhang et al., 1987).

In the present work, amino acid substitution experiments have been used in conjunction with the Epitope Scanning procedure to delineate the amino acids at the critical binding site of the serovar L1 epitope essential for $\mathrm{mAb}$ binding. Based on these results, single and multiple replacement heteroclitic peptides were synthesized, some of which showed enhanced reactivity with the antibody. The corresponding free peptides were then tested as immunogens in mice and their reactivity with native EB assessed.

\section{METHODS}

Synthesis of solid-phase peptides. Solid-phase peptides were synthesized using a commercially available kit (Cambridge Research Biochemicals) as previously described (Conlan $e t$ al., 1988). Sequences selected for synthesis were derived from the amino acid sequence of $C$. trachomatis MOMP, serovar L1 (Pickett et al., 1987). Hexameric peptides covering the typespecific region VKKDAVPNMS in VS2 were synthesized with 5 amino acid overlap. On the basis of amino acid substitution studies, single and multiply substituted heteroclitic peptides were also synthesized and the amino acid substitutions are shown underlined.

Solid-phase peptide enzyme immunoassay (EIA). The solidphase peptides as antigens were tested by EIA with two different serovar L1-specific $\mathrm{mAbs}$ raised against $C$. tracbomatis $\mathrm{L} 1 / 440 / \mathrm{Bu}$ EBs. The mAb 5F9 was originally described by Conlan et al. (1988) and mAb L1/27/1B1/G7 was kindly provided by Dr W. Newhall, Indiana University School of Medicine, USA. The EIA was performed and controlled according to the manufacturer's recommendations and as detailed by Conlan et al. (1988).

Synthetic peptides. Six peptides (DSAVPN, LDAVPL, $\underline{Y D A V P Y}, \mathrm{~K} \underline{\mathrm{S}} A V \underline{\mathrm{GY}}, \underline{\mathrm{DS}} \mathrm{AVGY}$ and DAVPYL), selected as highly reactive in solid-phase EIA, plus two control peptides (KDAVPN and DAVPNM), were synthesized manually with FMOC (fluorenylmethoxycarbonyl) chemistry using preactivated pentafluorophenyl (OPfp) esters by the Department of Immunology, University of Uppsala. Peptides were deprotected and cleaved from the resin with trifluoroacetic acid containing appropriate scavengers. The resin was removed by filtration and the peptides precipitated with diethyl ether. Analysis by plasma desorption mass spectrometry showed the presence of the expected $m / z$ as a major component. The peptides were therefore used without further purification. To mimic the structure of peptides bound to the pins, and to facilitate coupling to carrier proteins, an extra spacer alanine and a cysteine residue were added at the $\mathrm{C}$-terminus of all eight peptides and the $\mathrm{N}$ termini were acetylated.

Activation of carrier proteins. The peptides were coupled to carrier proteins for immunization studies and to facilitate binding to microtitre plates. The carrier proteins, ovalbumin or bovine serum albumin (BSA) (Sigma), were dissolved $\left(5 \mathrm{mg} \mathrm{ml}^{-1}\right)$ in phosphate-buffered saline (PBS; $10 \mathrm{mM}$ sodium phosphate, $150 \mathrm{mM} \mathrm{NaCl}, \mathrm{pH} \mathrm{7 \cdot 2)}$. Iodoacetamide (10:1 molar ratio) was added to block the free $\mathrm{SH}$-groups of the protein. After dialysis against PBS $\left(4 \times 1\right.$ litres at $4{ }^{\circ} \mathrm{C}$ for $\left.18 \mathrm{~h}\right)$ to remove excess iodoacetamide, the carrier proteins were activated prior to conjugation with the heterobifunctional coupling reagent $N$-succinimidyl 3-(2-pyridyldithio)propionate (SPDP; Pharmacia Biotech) at a molar ratio of $40: 1$ for ovalbumin and $60: 1$ for BSA. SPDP reacts with amino groups, introducing 2pyridyl disulphide groups which can react with free $\mathrm{SH}$-groups to form disulphide bridges. Activation was achieved by dropwise addition of SPDP ( $32 \mathrm{mM}$ in $95 \%, \mathrm{v} / \mathrm{v}$, ethanol) to 
the proteins. After reaction for $30 \mathrm{~min}$ at $21^{\circ} \mathrm{C}$, excess SPDP was removed by dialysis as above. The degree of activation was measured according to the manufacturer's instructions by adding excess dithioerythritol $(50 \mu$ lof $100 \mathrm{mM})$ to an aliquot of the protein solution and measuring the concentration of released pyridine-2-thione from its absorbance at $343 \mathrm{~nm}$. The activated proteins were kept at $-20{ }^{\circ} \mathrm{C}$ until coupling.

Coupling of peptides to carrier proteins. Each of the eight peptides was initially dissolved in $95 \%$ ethanol. Varying amounts of distilled water were added to each peptide solution to reduce the ethanol concentration while still retaining solubility. The final concentration was $1 \mathrm{mg}$ peptide $\mathrm{ml}^{-1}$ and the amount of ethanol in the final samples did not exceed $40 \%$ $(\mathrm{v} / \mathrm{v})$. Half a milligram of activated ovalbumin in PBS $\left(2.9 \mathrm{mg} \mathrm{ml}^{-1}\right)$ was reacted with a 40 -fold molar excess of peptide. For BSA, $0.3 \mathrm{mg}$ of activated protein $\left(4.0 \mathrm{mg} \mathrm{ml}^{-1}\right)$ was coupled with a 60 -fold molar excess of peptide over protein. The coupling steps were performed in a $1 \mathrm{ml}$ spectrophotometer cuvette and the absorbance monitored at $343 \mathrm{~nm}$. After the completion of coupling (between 0.75 and $4.5 \mathrm{~h}$ ) the samples were dialysed and stored in PBS at $-20^{\circ} \mathrm{C}$. Final concentrations of the conjugated proteins were $0.17 \mathrm{mg} \mathrm{ml}^{-1}$ for ovalbumin and $0 \cdot 10 \mathrm{mg} \mathrm{ml}^{-1}$ for BSA.

Immunization. Outbred mice (female, 4-5 weeks old, $18 \mathrm{~g}$ ), of strain NMRI (A-lab, Stockholm, Sweden), were used for immunization. Control sera immediately prior to immunization were collected from the tail vein. Mice were immunized subcutaneously in the neck with ovalbumin-peptide conjugate (10 $\mu \mathrm{g}$ per injection) emulsified in Freund's complete adjuvant (Sigma). For each conjugate, ten mice were inoculated. Animals were boosted on day 14 with equal amounts of conjugate in incomplete Freund's adjuvant and bled out on day 28 .

Organism. C. trachomatis, $\mathrm{L} 1 / 440 / \mathrm{Bu}$, was grown in suspension cultures of murine macrophage cells (WEHI-3) (Fröman $e t$ al., 1992). The cells were grown to a density of $4 \times 10^{5} \mathrm{ml}^{-1}$ in 1 litre spinner culture flasks (Bellco Glass) at $37^{\circ} \mathrm{C}$. An inoculum of chlamydiae equal to $10 \mu \mathrm{g}$ protein was added and the progress of infection monitored by immunofluorescence (Direct Specimen Test, Syva Co.). After 4-5 d, the EBs were separated from cell debris by sonication for $5 \mathrm{~min}$ in an ultrasonic bath (Branson 2200) followed by centrifugation at $1300 \mathrm{~g}$ and harvesting from the resulting supernatant at $11000 \mathrm{~g}$.

EIA. Microtitre plates (flat-well, Sterilin) were coated with BSA-peptide conjugate $\left(1 \mu \mathrm{g} \mathrm{ml}^{-1}, 100 \mu \mathrm{l}\right.$ per well), or with $10 \mu \mathrm{g}$ of $C$. trachomatis EB per $\mathrm{ml}$ of PBS $(100 \mu \mathrm{l}$ per well $)$ at $4{ }^{\circ} \mathrm{C}$ overnight. All dilutions of sera were made in PBS with $0.1 \%$ $(\mathrm{w} / \mathrm{v})$ BSA. Horseradish-peroxidase-conjugated rabbit antimouse Ig antibody (Dakopatts) was used as secondary antibody. Primary and secondary antibodies were incubated for $1 \mathrm{~h}$ at $37^{\circ} \mathrm{C}$. The substrate was $8.3 \mathrm{mM} o$-phenylenediamine dihydrochloride (Sigma) in $0.1 \mathrm{M}$ sodium acetate ( $\mathrm{pH} 5.0$ ) with $0.003 \%$ (v/v) $\mathrm{H}_{2} \mathrm{O}_{2}$. The reaction was terminated after $30 \mathrm{~min}$ at $37^{\circ} \mathrm{C}$ by adding $100 \mu \mathrm{l} 1 \mathrm{M} \mathrm{H}_{2} \mathrm{SO}_{4}$, and the absorbance was determined at $490 \mathrm{~nm}$. Each indivdiual serum was tested against the immunizing peptide. Sera for each immunizing antigen were also pooled and tested against each peptide or against whole EBs.

Competitive EIA. Inhibition experiments and calculations were performed according to the method of van Dam et al. (1989). Briefly, sera at appropriate dilutions were incubated overnight at $4{ }^{\circ} \mathrm{C}$ with different concentrations $(1-200 \mu \mathrm{M})$ of inhibitor peptide. After incubation, $100 \mu$ l aliquots of the mixtures were dispensed into antigen-coated plates and the EIA performed as described above.

\section{RESULTS}

\section{Characterization of MOMP epitopes and reactivity of heteroclitic peptides}

The critical binding sites of mAbs $5 \mathrm{~F} 9$ and $\mathrm{L} 1 / 27$ / 1B1/G7 at the serovar L1 specific epitope on MOMP had previously been defined as DAVP (Conlan et al., 1988). Single amino acid substitution of each of these amino acids at each position for all the other 19 naturally occurring L-amino acids was performed to indicate primary structural requirements for binding (Ward, 1992). It was found that aspartate at position 1 could be substituted by asparagine, tryptophan, serine or threonine. However negative charge alone was insufficient, as glutamate was ineffective. Alanine and valine at positions 2 and 3 were essential for binding. At position 4 proline could be substituted most effectively by cysteine or glycine, both of which are small amino acids likely to induce a $\beta$-turn. In some instances the substituted peptides bound the $\mathrm{mAb}$ more effectively than the native sequence. Based on this information we synthesized a series of multiply substituted peptides, in which the alanine and valine were kept constant, and the remaining amino acids were altered for amino acids effective as single substituents. In addition, as hydrophobic amino acids surrounding the critical binding site are thought to enhance antigen-antibody complex formation by favouring the exclusion of water molecules, we synthesized peptides with this feature. The peptides synthesized are listed in Table 1 , and Fig. 1 shows the reactivity of $\mathrm{mAb} 5 \mathrm{~F} 9$ with these peptides.

The reactivities of $\mathrm{mAbs} 5 \mathrm{~F} 9$ and $\mathrm{L} 1 / 27 / 1 \mathrm{~B} 1 / \mathrm{G} 7$ were similar, reacting with some of the heteroclitic peptides with almost ninefold greater absorbance than with the cognate (native sequence) peptide (Fig. 1), although $\mathrm{L} 1 / 27 / 1 \mathrm{~B} 1 / \mathrm{G} 7$ was a weaker $\mathrm{mAb}$. Both $\mathrm{mAbs}$ reacted strongly with DSAVPN, YDAVP $\underline{Y}, \mathrm{~K} \underline{\mathrm{S}} A V \underline{\mathrm{G}}$, DSAVGY and DAVPYL. Unfortunately, complete testing of $\mathrm{mAb} L 1 / 27 / 1 \mathrm{~B} 1 / \mathrm{G} 7$ with all peptides was impossible due to the limited amounts available.

To ensure that the high absorbances recorded were not due to non-specific binding of antibody to the solid-phase peptides, two of the reactive, hydrophobic and charged hexameric sequences as well as one tetramer sequence were synthesized with the reversed-order sequences PVAD, NPVASD and YGVA $\underline{S D}$. None of these control peptides reacted with any of the sera tested (Fig. 1).

\section{Antibody response to synthetic peptides}

Six of the heteroclitic peptides giving the highest reactivity with the mAbs (DSAVPN, LDAVPL,

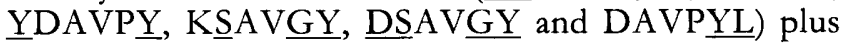
two native sequence peptides (KDAVPN and DAVPNM) were synthesized and coupled to ovalbumin at ratios between 3.3 and 8.6 peptides per carrier molecule (Table 2). The same peptides were also coupled to BSA for use as EIA antigens, at ratios between 10 and 22 peptides per molecule (Table 2), and the reactivity of $\mathrm{mAb} 5 \mathrm{~F} 9$ with these peptides was confirmed. Following immunization, 
Table 1. Summary of amino acid sequences, derived from the $C$. trachomatis serovar L1 MOMP sequence, synthesized on solid-phase pins and used in solid-phase peptide EIA with mAbs and polyclonal sera

Underlined amino acids indicate substitutions resulting in nonnative sequence.

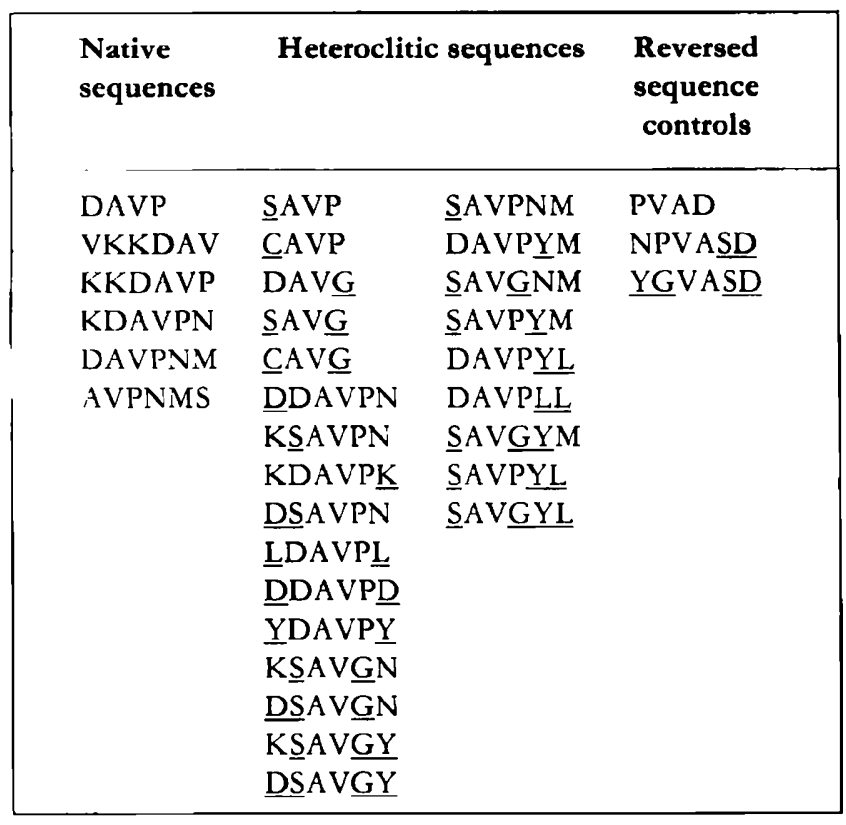

Table 2. Mean degree of substitution of activated amino groups with peptide per carrier molecule as determined by spectrophotometric measurement of the release of pyridine-2-thione during coupling

\begin{tabular}{|c|c|c|}
\hline \multirow[t]{2}{*}{ Peptide sequence } & \multicolumn{2}{|c|}{$\begin{array}{c}\text { Mean degree of coupling } \\
\text { (mol peptide per mol carrier) }\end{array}$} \\
\hline & Ovalbumin & BSA \\
\hline KDAVPN & $7 \cdot 3$ & 18 \\
\hline DAVPNM & 6.6 & 18 \\
\hline DSAVPN & 6.2 & 18 \\
\hline$\underline{\mathrm{I}} \mathrm{D} A \vee P \underline{\underline{L}}$ & $7 \cdot 1$ & 18 \\
\hline YDAVPY & $3 \cdot 3$ & 10 \\
\hline K $\underline{S A V G Y}$ & $5 \cdot 4$ & 22 \\
\hline$\underline{D S} \Lambda V G \bar{Y}$ & $3 \cdot 7$ & 16 \\
\hline DAVPYL & $8 \cdot 6$ & 13 \\
\hline
\end{tabular}

pooled antibody responses of 10 animals to the homologous ovalbumin-coupled peptides were measured by EIA (Fig. 2).

The heteroclitic sequence peptides were generally more immunogenic than the native sequence peptides when tested against the homologous antigen. The antibody dilutions at a $50 \%$ reduction of maximum absorbance at $490 \mathrm{~nm}$ were $1: 15000$ and $1: 9500$ for the native sequence immunogens DAVPNM and KDAVPN, but ranged from

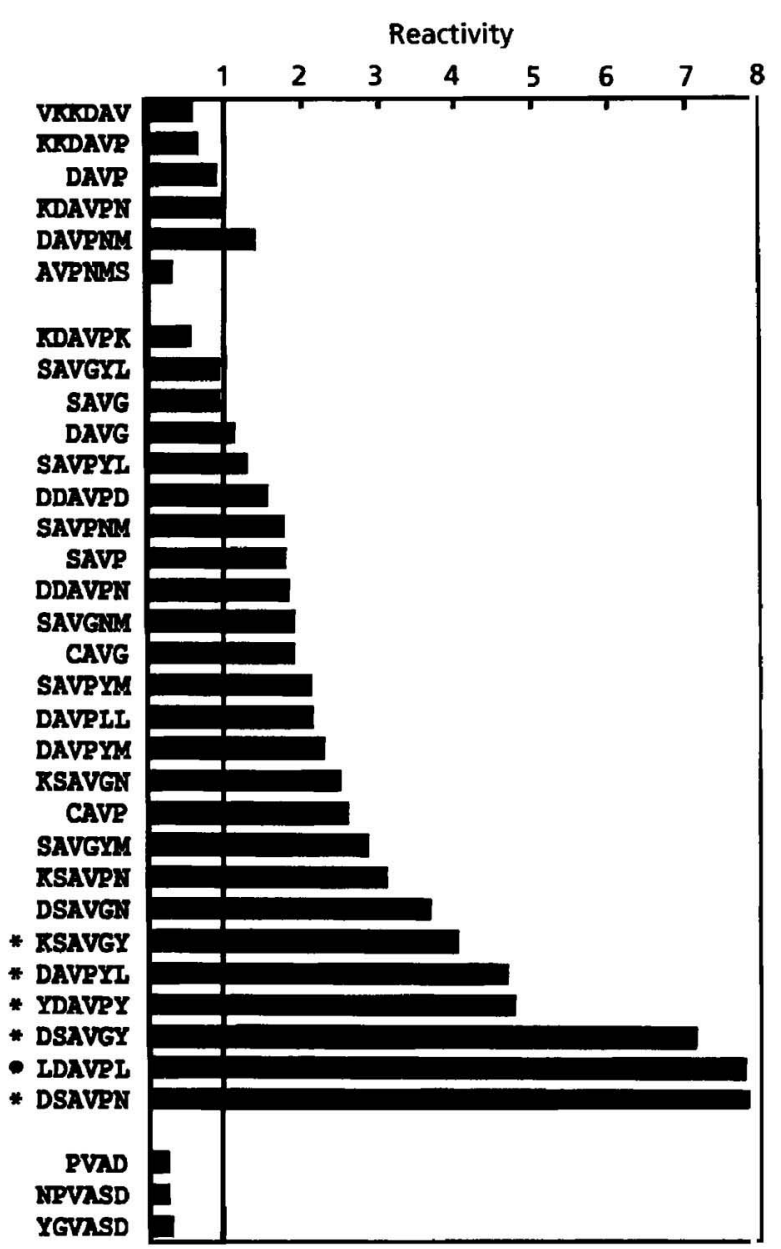

Fig. 1. Summary of the reactivities of MAb $5 F 9$ to native and heteroclitic peptides covering the VS2 region of $C$. trachomatis MOMP (serovar L1) when tested in solid-phase peptide EIA. The reactivity is described as the ratio between the absorbance values for test peptide and the native sequence peptides containing the minimal antibody-binding site DAVP. Asterisks indicate peptides selected for further experiments.

$1: 17500$ to $1: 41000$ for the heteroclitic peptides. The highest titre was observed for YDAVPY. Table 2 shows that the higher antibody responses to the heteroclitic sequences could not be attributed to increased amounts of

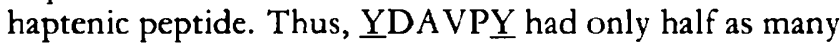
peptides coupled to the carrier as KDAVPN.

The reactivity of pooled antisera to each of the peptides was also assessed (data not shown). In general, all the pooled sera except that to $\underline{\mathrm{DS}} \mathrm{AVPN}$ reacted best with the corresponding homologous peptide. The pooled sera could be divided into two groups of reactivity. The first group consisted of antisera to KDAVPN, DSAVPN, $\underline{L} D A V P \underline{L}$ and DAVPYL which recognized several nonhomologous sequences. Anti-DSAVPN, in particular, reacted equally well with DSAVPN and KDAVPN. The second group, sera against DAVPNM, YDAVPY, KS $A V G Y$ and $\underline{D S A V G Y}$, were much more specific to the homologous peptide itself. 


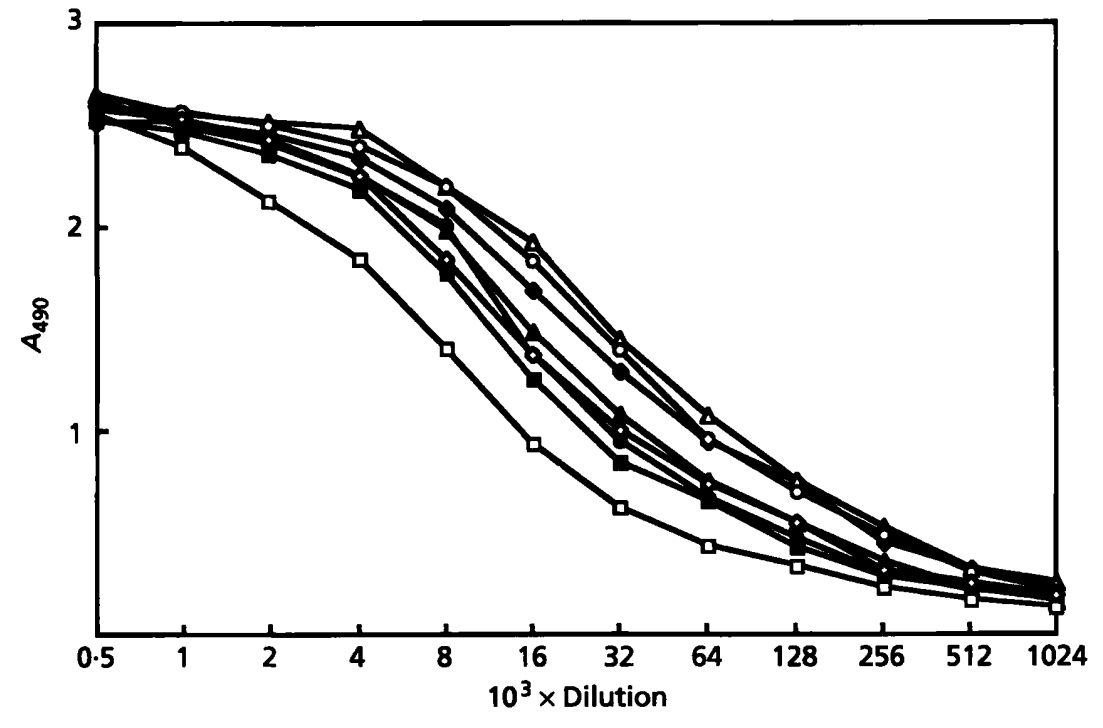

Fig. 2. Titration curves for twofold dilutions of pooled antisera, ten mice per immunizing ovalbumin-coupled peptide, when tested against homologous BSA-coupled peptide antigen. $\square$, KDAVPN; $\square$, DAVPNM; $\diamond$, DSAVPN; $\diamond$, LDAVPL; $\triangle$, YDAVPY; $\triangle$, KSAVGY; O, DSAVGY;, DAVPYL.
Table 3. Concentrations of free peptide needed to give a $50 \%$ reduction in antibody binding to homologous BSA-coupled antigen in EIA

\begin{tabular}{|c|c|}
\hline Peptide & Concn $(\mu \mathrm{M})$ \\
\hline KDAVPN & 200 \\
\hline DAVPNM & $>200$ \\
\hline$\underline{\text { DSAVPN }}$ & $>200$ \\
\hline$\overline{\mathrm{LD}} \mathrm{AVPL}$ & 30 \\
\hline$\underline{Y} D A V P Y$ & 200 \\
\hline$\overline{\mathrm{K}} \underline{\mathrm{S}} \mathrm{AV} \underline{\mathrm{G}} \overline{\mathrm{Y}}$ & 110 \\
\hline$\underline{\mathrm{DS}} A V \overline{\mathrm{GY}}$ & 170 \\
\hline$\overline{\mathrm{DAVPYL}}$ & $\gg 200$ \\
\hline
\end{tabular}

\section{Competitive EIA with free peptide}

Inhibition experiments were performed to compare the concentration of free peptide leading to a $50 \%$ reduction in antibody binding by EIA to the homologous BSAcoupled peptide ('Table 3 ). LDAVPL showed particularly effective inhibition of binding, while another, closely related heteroclitic peptide, DAVPYL, displayed almost no inhibitory capacity. This suggests that LDAVPL produced high-avidity antibodies to itself, whereas DAVPYL produced low-avidity antibodies.

\section{Antibody response to whole chlamydial EBs}

The antipeptide sera were tested by EIA against native MOMP on whole EBs. Pooled sera were tested in triplicate at twofold dilutions from $1: 10$ to $1: 640$, using preimmune sera as controls. All the test peptides produced some antibody reactive with EBs following immunization. Surprisingly, immunization with the native sequence peptide, DAVPNM, elicited the poorest response to whole EBs while the heteroclitic peptide YDAVPY generated antibodies which at all dilutions showed significantly higher ( $t$-test on means, $P<0.05$ ) reactivity to EBs (Fig. 3) than sera raised against native sequence peptides. At higher dilutions $(>1: 160)$, the pooled sera raised against K $\underline{S} A V \underline{G}$ were also significantly better $(P<0.05)$ at recognizing EBs than antisera to the native KDAVPN sequence peptide. The remaining heteroclitic sequences, i.e. DSAVPN, LDAVPL, DSAVGY and

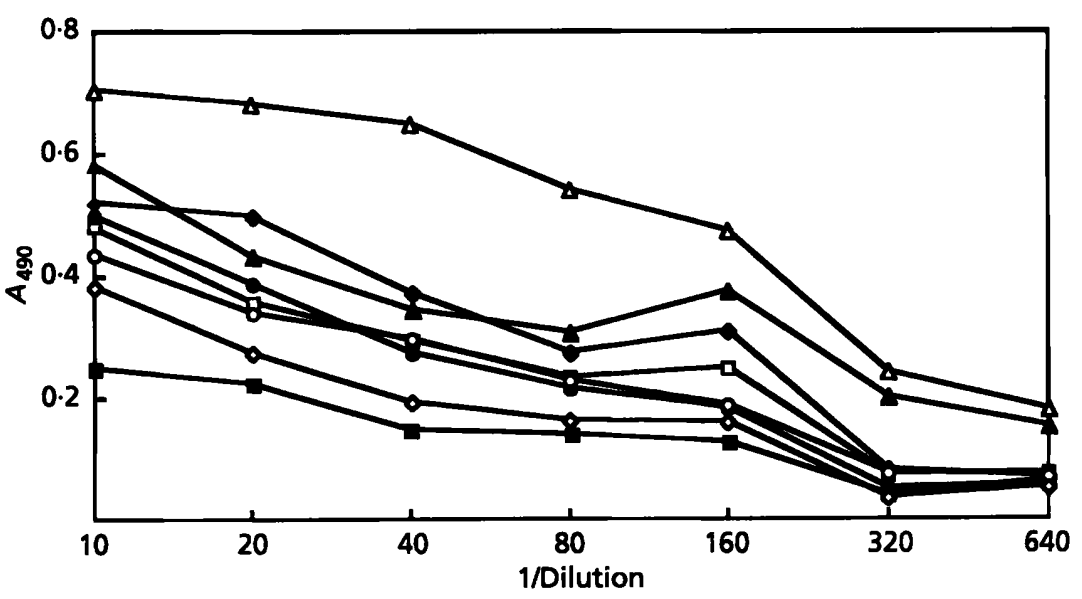

Fig. 3. Crossreactivity of antibodies in antipeptide sera with native C. trachomatis serovar L1 EBs. Dilution series of the different pooled antisera as defined in Fig. 2 were tested in EIA against whole EBs. 
DAVPYL, gave rise to sera with a recognition capacity close to KDAVPN.

\section{DISCUSSION}

Peptides are of interest both for vaccine development and for immunodiagnosis but the potential uses of mimotopic or heteroclitic peptides have received little study. Using $\mathrm{mAbs}$ to the native serovar-specific epitope on the MOMP of $C$. trachomatis serovar $\mathrm{L} 1$, we first set out to define whether alterations in amino acids within and around the critical binding site could enhance the reactivity of antibody with the resulting solid-phase peptides. This proved to be the case: antibody to a number of the heteroclitic sequences had almost ninefold higher binding capacity for antibody to the native protein than peptides of cognate sequence. It was striking that both serovar L1 specific $\mathrm{mAbs}$, produced in two different laboratories, recognized DAVP as their critical binding site (Conlan $e t$ al., 1988) and both, in this study, showed specificity for similar heteroclitic peptides. Specificity of binding was further confirmed by the fact that the mAbs failed to bind to reversed-sequence peptides with the same overall charge and hydrophobicity as two of the most reactive heteroclitic peptides. Thus the enhanced binding of $\mathrm{mAbs}$ to these heteroclitic peptides could not be attributed to altered charge or hydrophobicity. The mAb 5F9 has previously shown similar specificity for the critical binding peptide DAVP, as it does not react with the reversed peptide PVAD (Conlan et al., 1988). Amino acid substitutions around the critical AV essential for binding may lead to refolding of the peptide chain so that $\mathrm{AV}$ residues are more available for interaction with antibody. This would be particularly favoured by flanking hydrophobic substitutes, as in YDAVPY or LDAVPL, where hydrophobic interaction might favour chain folding. Hydrophobicity would also help in excluding water molecules from the combining site, facilitating a stronger binding to the antibody (Geysen et al., 1987). Thus it seems likely that the increased reactivity of the heteroclitic peptides for these $\mathrm{mAbs}$ is due to enhanced, if fortuitous, conformational fit with antibody to the native epitope.

Similar results were also reported for a nonameric peptide corresponding to an epitope generating a transmission blocking $\mathrm{mAb}$ to the $25 \mathrm{kDa}$ surface protein of Plasmopodium falciparium sexual stages (van Amerongen et al., 1992). Single amino acid replacement studies resulted in the synthesis of a peptide in which six of the nine amino acids were substituted, resulting in a dramatic thousandfold enhanced reactivity of the solid-phase mimotope with the mAb. However, the authors failed to show whether immunization with this peptide generated antibody capable of enhanced binding to the native malarial protein.

Our original hope was that, by comparing the amino acid substituents which were accepted for binding in the $\mathrm{F}(\mathrm{Ab})_{2}$ internal image of the native epitope, we might learn something of the conformation of this critical serovar-specific region, which, for $C$. trachomatis, is associated with neutralization (Zhang et al., 1987).
Attempts to apply molecular modelling to these short sequence peptides proved discouraging. Thus it proved impossible to conclude that a given hexapeptide favoured a particular energy-minimized structure, even when interactions with surrounding water molecules were included in the simulation. Direct attempts to detect ordered structures in solution using $500 \mathrm{MHz}$ nuclear magnetic resonance spectroscopy were also unsuccessful. Furthermore the contribution which the solid-phase support makes to the peptide conformation is also unknown. Ideally, free-solution peptides should be used for the initial evaluation of antigenicity; this is now feasible with new techniques of multiple peptide synthesis such as the Cleavable Peptides procedure. Larger peptides ( $>20$ amino acids) might be preferable because of the greater probability of ordered structure in aqueous solution (Satterthwait et al., 1988).

Our results, and those of van Amerongen et al. (1992), suggest that altered sequence peptides may have enhanced reactivity compared with native sequence peptides. This has obvious implications for the peptide-based assay of antibody in patient sera for the diagnosis of infection. Peptides corresponding to native MOMP sequences have recently been used for the sequence-defined immunoassay of sera from 33 trachoma patients (Jones et al., 1992). Peptides offer exquisite specificity for serodiagnosis; in a survey of tear antibodies among 1344 individuals in a village with endemic trachoma, it has proved possible using cognate sequence peptides to discriminate antibodies to variants differing in only one amino acid at the serovar A type specific epitope in VS1 (F. Ferris \& M. E. Ward, unpublished). Heteroclitic peptides with increased binding avidity for target antibody might further improve the sensitivity of antibody detection, but it will be necessary to confirm that specificity is not compromised. This is currently under investigation.

For vaccine development, the key question is whether heteroclitic peptides which show improved antigenicity also show improved immunogenicity in generating antibody to the target epitope. The immunization experiments indicated that all the peptide conjugates produced roughly equivalent magnitude of antibody to themselves, with the $1: 9500$ titre of the least immunogenic peptide (KDAVPN) roughly fourfold less than the 1:41000 titre of antiserum to the most immunogenic peptide. The fact that these experiments for each antigen were based on pooled sera from 10 different animals and that there was no correlation with the ratio of haptenic peptide to protein suggests that these results reflect minor differences in the immunogenicity of each preparation. Titres of the pooled antipeptide sera to whole chlamydial EB were approximately 1000 -fold less than to the homologous peptide. This may in part be due to the fact that the molarity of the epitope available for reaction is vastly greater when peptide is used as the antigen. Nevertheless it seems likely that the conformation of the antibodies was still a major limiting factor. However, antibody to the heteroclitic peptide YDAVPY showed markedly greater reactivity with whole $E B$ than did antisera to any of the other peptides; the markedly higher absorbance at each 
dilution suggests that this was probably due to increased avidity of these antibodies for EB. This was not reflected in the avidity of this antipeptide serum for the immunizing peptide as shown by competitive EIA.

We conclude that heteroclitic peptides may offer real advantages for the immunodiagnosis of infectious disease. This warrants further investigation, testing the effects of amino acid substitution in free-solution peptides, as well as solid-phase peptides, on the binding of polyclonal antibodies to the target epitope. Our data support the concept that altered sequence peptides can generate antibodies crossreactive with the native epitope on a target protein. Given the importance of antigen conformation for the development of peptide vaccines we believe further work is justified to establish whether heteroclitic peptides offer a useful solution to this problem.

\section{ACKNOWLEDGEMENTS}

This work was made possible by financial support from SAREC, Stockholm, to both groups. We thank Dr J. Newhall for providing us with monoclonal L1/27/1B1/G7, Wayne Conlan for initial solid-phase peptide synthesis, and Anna Matyi and Wubshet Mamo for assistance with the animal work.

\section{REFERENCES}

van Amerongen, A., Beckers, P. J. A., Plasman, H. H., Schaaper, W. M. M., Sauerwein, R. W., Meuwissen, J. H. E. T. \& Meloen, R. H. (1992). Peptides reactive with a transmission-blocking monoclonal antibody against Plasmopodium falciparium Pfs25: 2000-fold affinity increase by PEPSCAN-based amino acid substitutions. Peptide Res 5, 269-274.

Baehr, W., Zhang, Y. X., Joseph, T., Su, H., Nano, F. E., Everett, K. D. \& Caldwell, H.D. (1988). Mapping antigenic domains expressed by Chlamydia trachomatis major outer membrane protein genes. Proc Natl Acad Sci US A 85, 4000-4004.

Bierzynski, A., Kim, P. S. \& Baldwin, R. L. (1982). A salt bridge stabilizes the helix formed by isolated C-peptide of RNase A. Proc Natl Acad Sci US A 79, 2470-2474.

Caldwell, H. D., Kromhout, J. \& Schachter, J. (1981). Purification and partial characterization of the major outer membrane protein of Cblamydia trachomatis. Infect Immun 31, 1161-1176.

Cheetham, J. C., Raleigh, D. P., Griest, R. E., Redfield, C., Dobson, C. M. \& Rees, A. R. (1991). Antigen mobility in the combining site of an antipeptide antibody. Proc Natl Acad Sci US A 88, 7968-7972.

Conlan, J. W., Clarke, I. N. \& Ward, M. E. (1988). Epitope mapping with solid-phase peptides: identification of type-, subspecies-, species- and genus-reactive antibody binding domains on the major outer membrane protein of Chlamydia tracbomatis. Mol Microbiol 2, 673-679.

van Dam, G. J., Verheul, A. F. M., Zigterman, G. J. W. J., de Reuver, M. J. \& Snippe, H. (1989). Estimation of the avidity of antibodies in polyclonal antisera against Streptococcus pneumoniae type 3 by inhibition ELISA. Mol Immunol 26, 269-274.

Dyson, H. J., Rance, M., Houghten, R. A., Wright, P. E. \& Lerner, R. A. (1987). The order-disorder paradox in antigen-antibody union: antipeptide antibodies as a probe for structured regions of small peptides. In Biological Organization: Macromolecular Interactions at High Resolution, pp. 227-234. Edited by R. M. Burnett \& H. J. Vogel. New York: Academic Press.

Dyson, H. J., Rance, M., Houghten, R. A., Lerner, R. A. \& Wright, P. E. (1988). Folding of immunogenic peptide fragments of proteins in water solution. I. Sequence requirements for the formation of a reverse turn. J Mol Biol 201, 161-200.

Fröman, G., Yxfeldt, G., Wilén-Winter, B., Grönvik, K.-O. \& Mårdh, P.-A. (1992). Large scale growth of Chlamydia tracbomatis in macrophage suspension. In 2 Proceedings of the European Society for Chlamydia Research, p. 24. Edited by P.-A. Mårdh, M. La Placa \& M. Ward. Stockholm: Uppsala University Centre for STD Research.

Getzoff, E. D., Geysen, H. M., Rodda, S. J., Alexander, H., Tainer, J. A. \& Lerner, R. A. (1987). Mechanisms of antibody binding to a protein. Science 235, 1191-1196.

Geysen, H. M., Rodda, S. J., Mason, T. J., Tribbick, G. \& Schoofs, P. G. (1987). Strategies for epitope analysis using peptide synthesis. $J$ Immunol Methods 102, 259-274.

Jones, H. M., Schachter, J. \& Stephens, R. S. (1992). Evaluation of the humoral immune response in trachoma to Chlamydia trachomatis major outer membrane proteins by sequence-defined immunoassay. J Infect Dis 166, 915-919.

Pickett, M. A., Ward, M. E. \& Clarke, I. N. (1987). Complete nucleotide sequence of the major outer membrane protein gene from Chlamydia trachomatis serovar L1. FEMS Microbiol Lett 42, 185-190.

Rini, J. M., Schulze-Gahmen, U. \& Wilson, I. A. (1992). Structural evidence for induced fit as a mechanism for antibody-antigen recognition. Science 255, 959-965.

Satterthwait, A. C., Arrhenius, T., Hagopian, F. A., Zavala, F., Nussenzweig, V. \& Lerner, R. A. (1988). Conformational restriction of peptidyl immunogens with covalent replacements for the hydrogen bond. Vaccine 6, 99-103.

Schachter, J. \& Dawson, C. (1978). Chlamydial Infections. Littleton, Massachusetts: PSA Publishing.

Ward, M. E. (1992). Chlamydial vaccines - future trends. J. Infect 25, 11-26.

Yuan, Y., Zhang, Y. X., Watkins, N. G. \& Caldwell, H. D. (1989). Nucleotide and deduced amino acid sequences for the four variable domains of the major outer membrane proteins of the 15 Chlamydia trachomatis serovars. Infect Immun 57, 1040-1049.

Zhang, Y. X., Stewart, S., Joseph, T., Taylor, H. R. \& Caldwell, H. D. (1987). Protective monoclonal antibodies recognize epitopes located on the major outer membrane protein of Chlamydia trachomatis. J Immunol 138, 575-581.

Received 8 June 1993; revised 2 September 1993; accepted 28 October 1993. 